\title{
Amplifying Signals and avoiding surprises: Potential synergies between ICOS and eLTER at the Water-Climate-Greenhouse Gas nexus
}

Futter, Martyn

2021-03-04

Futter, M , Alam , S A , Baatz , R, Bäck, J , Diaz-Pines , E, Dick , J , Forsius , M , Gaube , V , Gaube , V , Jones, M , Nikolaidis, N , Poppe , C, Rankinen , K, Rowe , E , Schaub , M , Skiba, U M , Vereecken , H \& Dirnböck , T 2021, ' Amplifying Signals and avoiding surprises: Potential synergies between ICOS and ELTER at the Water-Climate-Greenhouse Gas nexus ' , EGU General Assembly 2021 , Vienna , Austria , 19/04/2021 - 30/04/2021 . https://doi.org/10.5194/eg

http://hdl.handle.net/10138/328651

https://doi.org/10.5194/egusphere-egu21-9567

cc_by

publishedVersion

Downloaded from Helda, University of Helsinki institutional repository.

This is an electronic reprint of the original article.

This reprint may differ from the original in pagination and typographic detail.

Please cite the original version. 
EGU21-9567, updated on 31 Mar 2021

https://doi.org/10.5194/egusphere-egu21-9567

EGU General Assembly 2021

(c) Author(s) 2021. This work is distributed under

the Creative Commons Attribution 4.0 License.

\section{Amplifying Signals and avoiding surprises: Potential synergies between ICOS and eLTER at the Water-Climate-Greenhouse Gas nexus}

Martyn Futter ${ }^{1}$, Syed Ashraful Alam² ${ }^{2}$ Roland Baatz ${ }^{3}$, Jaana Bäck ${ }^{4}$, Eugenio Diaz-Pines ${ }^{5}$, Jan Dick ${ }^{6}$, Martin Forsius ${ }^{7}$, Veronika Gaube ${ }^{8}$, Matthew Jones ${ }^{6}$, Nikolaos Nikolaidis ${ }^{9}$, Christian Poppe ${ }^{3}$, Katri Rankinen ${ }^{7}$, Ed Rowe $^{10}$, Marcus Schaub $^{11}$, Ute Skiba ${ }^{6}$, Harry Vereecken ${ }^{12}$, and Thomas Dirnböck ${ }^{13}$

${ }^{1}$ Aquatic Sciences and Assessment, Swedish University of Agricultural Sciences, Uppsala, SE (martyn.futter@slu.se)

${ }^{2}$ Faculty of Agriculture and Forestry, University of Helsinki, Helsinki, FI

${ }^{3}$ Institute of Bio- and Geosciences, Forschungszentrum Jülich, Jülich, DE

${ }^{4}$ Department of Forest Sciences, University of Helsinki, Helsinki FI

${ }^{5}$ Institute of Soil Research, BOKU, Vienna, AT

${ }^{6}$ Centre for Ecology and Hydrology, Edinburgh, UK

${ }^{7} \mathrm{SYKE}$, Helsinki, $\mathrm{FI}$

${ }^{8}$ Institute of Social Ecology, BIKU, Vienna, AT

${ }^{9}$ School of Environmental Engineering, Technical University of Crete, Chania, GR

${ }^{10}$ Centre for Ecology and Hydrology, Bangor, UK

${ }^{11}$ Ecophysiology Group, Swiss Federal Research Institute WSL, Birmensdorf, CH

${ }^{12}$ Forschungszentrum Jülich, Jülich, DE

${ }^{13}$ Environment Agency Austria, Vienna, AT

Environmental thresholds. tipping points and subsequent regime shifts associated with the water/climate/greenhouse gas nexus pose a genuine threat to sustainability. Both the ongoing forest dieback in Central Europe caused by the extreme droughts of the last years and the effect of global warming on ecosystem functioning have the potential to cause ecological surprise (sensu Lindenmayer et al. 2010) where ecosystems are pushed into new, unexpected and usually undesirable states.

Formulating appropriate scientific and societal responses to such regime shifts requires breadth, depth, intensity and duration of environmental, ecological and socio-ecological monitoring. Broad geographic coverage to encompass relevant biophysical and societal gradients, consideration of all appropriate parameters, adequate measurement frequency and long-term, standardized observations are all needed to provide reliable early warnings of severe environmental change, test ecosystem models, avoid double counting in carbon accounting and to reduce the likelihood of undesirable ecological outcomes. This is especially true of events driven by simultaneous changes in climate, the water cycle and human activities.

Well-supported, site-based research infrastructures (RIs; e.g., eLTER and ICOS) are essential tools 
with the necessary breadth, depth, intensity and duration for early detection and attribution of environmental change. Individually, the eLTER and ICOS RIs generate a wealth of data supporting the ecosystem and carbon research communities. Achieving synergies between the two RIs can add value to both communities and potentially offer meaningful insight into the European waterclimate-greenhouse gas nexus.

The unique insights into processes and mechanisms of ecosystem dynamics and functioning obtained from high intensity monitoring conducted by the ICOS RI greatly increase the likelihood of detecting signals of environmental change. These signals must be placed into the context of their long-term trajectory and potential societal and environmental drivers. The spatially extensive, long-term, multi-disciplinary monitoring conducted at LTER sites and LTSER platforms under the umbrella of the eLTER programme can provide this context.

Here, we outline one potential roadmap for achieving synergies between the ICOS and eLTER RIS focussing on the value of co-location for improved understanding of the water/climate/greenhouse gas nexus. Based on data and experiences from intensively studied research sites, we highlight some of the possibilities for reducing the likelihood of ecological surprise that could result from such synergies.

Lindenmayer, D.B., Likens, G.E., Krebs, C.J. and Hobbs, R.J., 2010. Improved probability of detection of ecological "surprises". Proceedings of the National Academy of Sciences, 107(51), pp.21957-21962. 